\title{
Evaluation of Grewa Venusta (Wild Jute Tree) Extract as Corrosion Inhibitor for Mild Steel in Acidic Environment
}

\author{
I.Y. Suleiman, ${ }^{a,{ }^{*}}$ Sani A. Salihu, ${ }^{b}$ O.S. Emokpaire, ${ }^{a}$ \\ O.C. Ogheneme ${ }^{c}$ and Lasisi Shuaibu ${ }^{a}$ \\ ${ }^{a}$ Department of Metallurgical Engineering, Waziri Umaru Federal Polytechnic, \\ Birnin Kebbi, Kebbi State, Nigeria \\ ${ }^{b}$ Department of Mechanical Engineering, Faculty of Engineering, Kebbi State University of \\ Science and Technology, Aliero, Kebbi State, Nigeria \\ ${ }^{c}$ Department of Mechanical Engineering, Waziri Umaru Federal Polytechnic, \\ Birnin Kebbi, Kebbi State, Nigeria
}

Received April 21, 2016; accepted December 21, 2016

\begin{abstract}
The feasibility of using extract of Grewa Venusta (wild jute tree) root as corrosion inhibitor with mild steel was investigated using gravimetric and electrochemical techniques in 1.0 M hydrochloric acid. The inhibitor's concentration, temperature and time were varied in the range of $0-10 \% \mathrm{v} / \mathrm{v}$ at $2 \% \mathrm{v} / \mathrm{v}$ interval, $30-75^{\circ} \mathrm{C}$ at $15^{\circ} \mathrm{C}$ interval and 1-6 hours at 1 hour interval. Characterizations of the extract were done by quantitative method (AAS) and Gas Chromatography-Mass Spectrometry (GC-MS). Scanning electron microscope (SEM) was used to analyze the surface morphology of the samples. The synergetic effect of the inhibitor was evaluated by addition of halide ions $\left(\mathrm{KBr}^{-}, \mathrm{KCl}^{-}\right.$and $\left.\mathrm{KI}^{-}\right)$. The results showed that corrosion rate increased with an increase in temperature, and decreased with an increase in inhibitor's concentration and time; maximum inhibition efficiency was $97.60 \%$ and $99.88 \%$ in the presence of $\mathrm{KI}^{-}$ addition, and was assumed to occur via adsorption of the inhibitor molecules on the metal surface. The extract contains metallic elements such as calcium, magnesium, mono acetate $\left(\mathrm{C}_{5} \mathrm{H}_{10} \mathrm{O}_{4}\right)$ and $4 \mathrm{H}$-Pyrazole $\left(\mathrm{C}_{9} \mathrm{H}_{10} \mathrm{~F}_{6} \mathrm{~N}_{2} \mathrm{~S}\right)$ that suppressed the anodic dissolution. The adsorption of the extract molecules on the mild steel surface obeys Langmuir adsorption isotherm. The results showed that the inhibitor acted as a mixedtype inhibitor.
\end{abstract}

Keywords: Adsorption isotherm; characterizations; GC-MS; SEM; halide ions.

\section{Introduction}

Engineering metals are unstable in natural and industrial environments. In the long term, they inevitably revert to stable chemical species akin to the chemically combined forms from which they were extracted. In that sense, metals are only

\footnotetext{
* Corresponding author. E-mail address: onoruoizadanjumas@yahoo.co.uk
} 
borrowed from nature for a limited time. Nevertheless, if we understand their interactions with the environments to which they are subjected, and take appropriate precautions, degradation can be arrested or suppressed long enough for them to serve the purposes required by [1]. Iron and steel are the most versatile, least expensive and most widely applied of the engineering metals, and they are unequaled in the range of mechanical and physical properties with which they can be endowed by alloying and heat-treatment [2]. The main disadvantage of iron and most alloys based on it is that they have poor resistance to corrosion in even relatively mild service environments, and usually need the protection of coatings or environment conditioning, according to [3]. This generalization excludes stainless iron and steel that are formulated with high chromium contents to change their surface chemistry.

Metals in service often give a superficial impression of permanence, but all, except gold, are chemically unstable in air and air-saturated water at ambient temperature, and most are also unstable in air-free water. Hence, almost all environments in which metals serve are potentially hostile, and their successful use in engineering and commercial applications depends on protective mechanisms [4]. In some metal/environment systems, the metal is protected by passivity, a naturally formed surface condition inhibiting reaction. In other systems, the metal surface remains active, and some form of protection must be provided by design. The study of mild steel corrosion which researches the most prolific, flexible, versatile and least expensive metallic materials is a matter of tremendous theoretical and practical concern and, as such, has received a considerable amount of interest [5]. Acids are widely used in industrial acid cleaning, descaling and pickling, and oil well acidizing, according to [6], and require the use of corrosion inhibitors, in order to restrain their corrosion attack on metallic materials. However, the applications of mild steel are greatly hindered by pitting and stress corrosion cracking, especially in hostile environments, such as acidic $\left(\mathrm{HCl}\right.$ and $\left.\mathrm{H}_{2} \mathrm{SO}_{4}\right)$ and halide - seawater. Acid is a good electrolyte and the $\mathrm{pH}$ lower than 7 can cause pitting and stress corrosion cracking, as observed by [7].

Several attempts have been made to solve the corrosion problems associated with mild steel in acidic environments, and one of the chosen methods was the use of corrosion inhibitors. However, most of these synthetic compounds show good anticorrosive action, and most of them are highly toxic to both human beings and the environment, according to [8]. The issue of toxicity has led investigations to focus on the use of naturally occurring substances, in order to find low-cost and non-hazardous inhibitors. Plant extracts have become important as an environmentally acceptable, readily available and renewable source of materials for a wide range of corrosion prevention formulations. Therefore, finding naturally occurring substances as corrosion inhibitors is a subject of great practical significance, according to [9-10]. Extracts of plant materials contain a wide variety of organic compounds. Most of them contain hetero-atoms, such as $\mathrm{P}, \mathrm{N}, \mathrm{S}, \mathrm{O}$. These atoms coordinate with the corroding metal atom (their ions), through their electrons. Therefore, protective films are formed on the metal surface and, hence, corrosion is prevented, according to [11]. The inhibition 
efficiency of plant extracts, in controlling corrosion of metals in various environments, has been investigated in acidic media [12-16].

In the present work, Grewa Venusta extract was found out to be a cheap, ecofriendly and naturally occurring substance, and its inhibitive action on the corrosion behaviour of mild steel in $1.0 \mathrm{M} \mathrm{HCl}$ was investigated through Gravimetric - weight loss and Potentiodynamic polarization (Tafel analysis) measurements at 30, 45, 60 and $75^{\circ} \mathrm{C}$ in an acidic environment. Kinetic and activation parameters that govern the metal corrosion were evaluated; the coupon surfaces were examined in the absence and presence of the corrosion inhibitor, using Scanning Electron Microscope (SEM), to find out the constituents that were responsible for the inhibition. The plant extract was characterized by Atomic Absorption Spectroscopy (AAS), Quantitative phytochemical screening and Gas Chromatography-Mass Spectrometry (GC-MS).

\section{Experimental procedures}

\section{Preparation of the plant extract}

The plant Grewa Venusta was obtained from Ahmadu Bello University, Zaria, dried, ground and soaked in a solution of ethanol for three days. The filtrate was subjected to evaporation in order to obtain the sample free of ethanol, using an evaporator. The stock solution, $2-10 \% \mathrm{v} / \mathrm{v}$ of the extract, was used to prepare different concentrations of the test solutions dissolved in 1.5 Litres of $1.0 \mathrm{M}$ hydrochloric acid.

\section{Preparation of mild steel specimen}

Mild steel rods were mechanically cut into a cylindrical shape of $20 \mathrm{~mm}$ by 10 $\mathrm{mm}$, with the chemical compositions shown in Table 1. The specimens were mechanically polished with emery papers of 80 to 800 grades, and subsequently degreased and stored in the desiccators to avoid re-oxidation. Weight of the samples was taken before and after the test.

Table 1. Chemical composition of the mild steel.

\begin{tabular}{|c|c|c|c|c|c|c|c|}
\hline $\mathbf{C}$ & $\mathbf{M n}$ & $\mathbf{S i}$ & $\mathbf{P}$ & $\mathbf{S}$ & $\mathbf{A l}$ & $\mathbf{N i}$ & $\mathbf{F e}$ \\
\hline 0.17 & 0.45 & 0.18 & 0.012 & 0.032 & 0.005 & 0.008 & Balance \\
\hline
\end{tabular}

\section{Weight loss measurements}

Previously polished and degreased specimens of size $20 \mathrm{~mm}$ by $10 \mathrm{~mm}$ were used for weight loss studies. Already weighed specimens were separately immersed in 250 milliliters $(\mathrm{mL})$ of $1.0 \mathrm{M} \mathrm{HCl}$ solutions containing $0,2,4,6,8$ and $10 \% \mathrm{v} / \mathrm{v}$ of $\mathrm{GV}$ extract, for 1, 2, 3, 4, 5 and 6 days. After the elapsed time the specimens were taken out, washed, dried and reweighed. All the experiments were performed in triplicate, and average values were recorded. The experiment was carried out at four different temperatures of $30,45,60$ and $75{ }^{\circ} \mathrm{C}$, respectively. From the measured weight loss data, the corrosion rate $(\mathrm{mm} / \mathrm{y})$ and the inhibition efficiency (IE) were calculated using equations 1 and 2 as in [12]: 


$$
C R=\frac{K W}{A t D}
$$

where $\mathrm{K}=8.76 \times 10^{4}$ (constant), $\mathrm{W}=$ weight loss in $\mathrm{g}, \mathrm{A}=$ area in $\mathrm{cm}^{2}, \mathrm{t}=$ time in hours, and $\mathrm{D}=$ density in $\mathrm{g} / \mathrm{cm}^{3}$ (7.86), respectively.

$$
I E \%=\frac{C R_{a}-C R_{p}}{C R_{2 \pi}} \times 100
$$

where, $C R_{a}$ and $C R_{p}$ are the corrosion rates in the absence and presence of inhibitor.

\section{Electrochemical measurements}

The electrochemical measurements were performed in a conventional threeelectrode assembly containing a cylindrical carbon steel specimen with an exposed area of $1 \mathrm{~cm}^{2}$ as working electrode (WE); a platinum foil of surface area $2 \mathrm{~cm}^{2}$ as counter electrode; and a saturated calomel electrode (SCE) provided with a Luggin capillary as a reference electrode. They were immersed in a $1 \mathrm{M}$ $\mathrm{HCl}$ solution until a steady-state open circuit potential (OCP) was obtained. Potentiodynamic polarization measurements were done using an Autolab potentiostat (PGSTAT30 computer controlled) with the General Purpose Electrochemical Software (GPES) package version 4.9. The $\mathrm{HCl}$ solution was degassed with ultrapure nitrogen bubbling to avoid any reactions with dissolved oxygen. Tafel polarization measurements were made for a potential range of -200 $\mathrm{mV}$ to $+200 \mathrm{mV}$ with respect to $\mathrm{OCP}$, at a scan rate of $1 \mathrm{mV} / \mathrm{s}$. From the electrochemical studies, corrosion potential and corrosion current were calculated. All the tests were performed at a temperature of $30{ }^{\circ} \mathrm{C}$. The inhibitor efficiency was evaluated using equation 3 as in [18].

$$
I E \%=\frac{i_{\text {FRT }}-i_{\text {FWT }}^{r}}{i_{\text {LaTT }}} \times 100 \%
$$

where $i_{\text {corm }}$ and $i_{\text {com }}$ are the corrosion current densities of mild steel in the absence and presence of the inhibitor, respectively.

\section{Determination of metallic cations in the extracts using AAS}

The Atomic Absorption Spectrophotometer (AAS) was used for the analysis of the following metals: $\mathrm{Mg}, \mathrm{Zn}, \mathrm{Fe}, \mathrm{Mn}, \mathrm{Cu}, \mathrm{Pb}$ and $\mathrm{P}$. Using AAS, a known amount of the sample was placed in a dish and heated with a Bunsen burner in a fume cupboard, until there was no more smoke emitted. This was transferred to the desiccator for it to cool down, after which a $0.1 \mathrm{M} \mathrm{HCl}$ solution was added to the ash. The resulting solution was filtered and diluted. Suitable salts of the metals in question were used to make their standards, lamps were fixed and the analyses were done. Using the flame photometer, the sample diluents were aspirated into the jenway digital flame photometer using the filter corresponding to each mineral element. All these were carried out using the method described in [17]. The experiment was carried out at the Industrial Chemical Laboratory, National Research Institute for Chemical Technology, Zaria. 


\section{Gas Chromatograph- Mass Spectrometry (GC-MS) analyses}

About $1 \mathrm{~mL}$ of each extract concentration was analyzed by GC-MS using QP 2010 Plus Schmadzu Product equipped with two fused-silica capillary columns, with $60 \mathrm{~m} \times 0.22 \mathrm{~mm}$, film thickness, at National Research Institute for Chemical Technology, Zaria. The conditions under which the experiment was carried out were the same as in previous work [12].

\section{SEM investigations}

The mild steel surface was prepared for SEM studies by keeping the specimens for one hour in the electrolyte, with and without the optimum concentrations of the inhibitor. The mild steel specimens were then washed with distilled water, dried and analyzed using SEM. A Philips model XL30SFEG scanning electron microscope was used for surface analysis, as described by [15].

\section{Results and discussion}

\section{Determination of phytoconstituents of the $G V$}

The results obtained from the quantitative method are presented in Table 2:

Table 2. Analytical results of phytochemical screening of the Grewa Venusta (GV).

\begin{tabular}{|c|c|c|c|c|c|c|c|}
\hline S/N & Plants & Alkaloids & Tannins & Saponins & Flavonoids & Glycosides & Volatile oil \\
\hline 1 & G.V & $1.21 \pm 0.45$ & $14.65 \pm 0.52$ & $2.99 \pm 0.87$ & $0.96 \pm 0.59$ & $0.43 \pm 10$ & $0.77 \pm 0.21$ \\
\hline
\end{tabular}

\section{Determination of metallic elements in the extracts using AAS}

Table 3 gives the metallic elements present in the Grewa Venusta extract, determined using Atomic Absorption Spectrophotometer (AAS).

Table 3. Chemical compositions of Grewa Venusta extract (metallic cations) from AAS analysis.

\begin{tabular}{|c|c|c|c|c|c|c|c|c|}
\hline Elements (mg/L)\% / Extracts & Ca & Mg & Cr & Co & Mn & Pb & Cu & Zn \\
\hline G.V & 75 & 18 & 1.34 & 1.21 & 2.21 & 1.22 & 0.76 & 0.23 \\
\hline
\end{tabular}

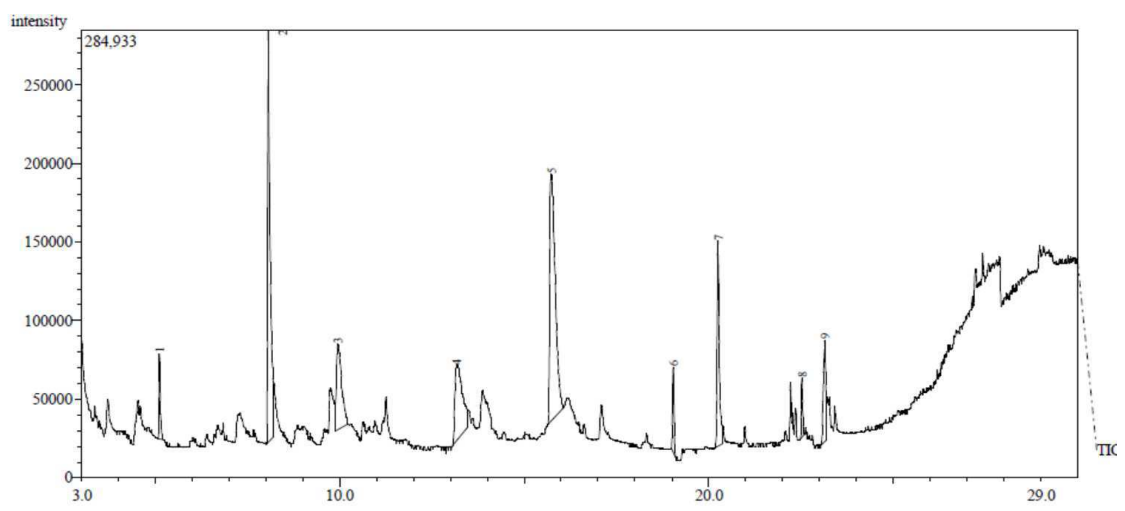

Figure 1. Chromatogram and corresponding mass spectra of $G V$ extract showing the peaks of the compounds. 


\section{Gas Chromatography- Mass Spectrometry (GC-MS) analyses}

Tables 4 and 5 show the results of GC-MS data of extract compounds identified in the ethanol distillate of GV by GC-MS analysis, while Figs. 1 and 2 show the GC-MS spectra and the structures of the compounds identified in the extract.

Table 4. GC-MS data of Grewa Venusta ethanolic extract.

\begin{tabular}{ccccccccc}
\hline \multicolumn{7}{c}{ Peak Report HC } \\
\hline Peak & R time & I time & F. time & Area & Area \% & Height & $\begin{array}{c}\text { Height } \\
\text { \% }\end{array}$ & A/H \\
1. & 5.119 & 5.083 & 5.217 & 134883 & 2.57 & 53829 & 6.23 & 2.51 \\
2. & 8.068 & 8.017 & 8.208 & 1201168 & 22.84 & 262173 & 30.34 & 4.58 \\
3. & 9.952 & 9.892 & 10.225 & 536040 & 10.19 & 54313 & 6.29 & 9.87 \\
4. & 13.182 & 13.067 & 13.458 & 681543 & 12.96 & 48799 & 5.65 & 13.97 \\
5. & 15.736 & 15.60 & 16.067 & 1585941 & 30.16 & 156761 & 18.14 & 10.12 \\
6. & 19.039 & 18.983 & 19.125 & 165650 & 3.15 & 54801 & 6.34 & 3.02 \\
7. & 20.250 & 20.167 & 20375 & 538550 & 10.24 & 130800 & 15.14 & 4.12 \\
8. & 22.526 & 22.475 & 22.592 & 101864 & 1.94 & 37913 & 4.39 & 2.69 \\
9. & 23.142 & 23.058 & 23.200 & 312818 & 5.95 & 64587 & 7.48 & 4.84 \\
& & & & 5258457 & 100.00 & 863976 & 100.00 & \\
\hline
\end{tabular}

Table 5. Chemical compounds identified in the ethanol distillate of Grewa Venusta $(G V))$ extract by GC-MS analysis.

\begin{tabular}{ccccc}
\hline Peaks & Extract & Compounds name & Molecular formula & $\begin{array}{c}\text { Molecular } \\
\text { weight g/mol }\end{array}$ \\
\hline 1 & & 2-Pentanone, 4-methoxy-4-methyl & $\mathrm{C}_{7} \mathrm{H}_{14} \mathrm{O}_{2}$ & 130 \\
2 & & 4H-Pyran-4-one, 2,3-dihydro-3 & $\mathrm{C}_{6} \mathrm{H}_{8} \mathrm{O}_{4}$ & 144 \\
3 & & 1,2,3-Propanetriol, mono acetate & $\mathrm{C}_{5} \mathrm{H}_{10} \mathrm{O}_{4}$ & 134 \\
4 & & 4H-Pyrazole, 3-tert-butylsulfanyl-4 & $\mathrm{C}_{9} \mathrm{H}_{10} \mathrm{~F}_{6} \mathrm{~N}_{2} \mathrm{~S}$ & 292 \\
5 & Grewa & Dodecanoic acid, 3-hydroxy- & $\mathrm{C}_{12} \mathrm{H}_{24} \mathrm{O}_{3}$ & 216 \\
6 & Venusta & Hexadecanoic acid, 15-methyl- & $\mathrm{C}_{18} \mathrm{H}_{36} \mathrm{O}_{2}$ & 284 \\
7 & $(G V)$ & Octadecanoic acid, Stearic acid & $\mathrm{C}_{18} \mathrm{H}_{36} \mathrm{O}_{2}$ & 284 \\
8 & & Cyclohexanol, 3,5-dimethyl & $\mathrm{C}_{8} \mathrm{H}_{16} \mathrm{O}$ & 128 \\
9 & & 1,9-Nonanediol, dimethanesulfonate & $\mathrm{C}_{11} \mathrm{H}_{24} \mathrm{O}_{6} \mathrm{~S}_{2}$ & 316 \\
\hline
\end{tabular}

\section{Weight loss studies}

Corrosion parameters obtained from weight loss method are presented in Table 6. The results indicate that the corrosion rates of mild steel decrease with an increase in the concentration of ethanol extract of Grewa Venusta. Also, the inhibition efficiency of Grewa Venusta decreases with an increase in temperature $[11,18]$. Fig. 3 shows the variation of inhibition efficiency with the extract in the presence of the corroding medium. The optimum concentration for Grewa Venusta was found to be $8 \% \mathrm{v} / \mathrm{v}$ with maximum inhibition efficiency of $97.90 \%$ for the period of 3 hours of immersion time. This result indicated that the plant extract could act as effective corrosion inhibitor for mild steel in $1.0 \mathrm{M} \mathrm{HCl}$, due to the compounds/elements determined by both analytical /quantitative method, AAS and GC-MS, shown in Tables 1, 2 and 4, respectively, supported by Figs. 1 
and $2[7,8,11,12]$. The effect of immersion time was studied for periods of $1 \mathrm{~h}$ to 6h, as shown in Table 7; it reveals that the plant extract showed maximum efficiency at $3 \mathrm{~h}$ of immersion time (as also illustrated in Fig. 4,) which is sufficient for the pickling process [16]. However, this behaviour has been attributed to the increase in the elements/compounds that form stable oxides. The thin layer of the oxides adhered to the metal surface, resulting in a decrease in the corrosion rate. Similar results have been reported by $[14,16]$.

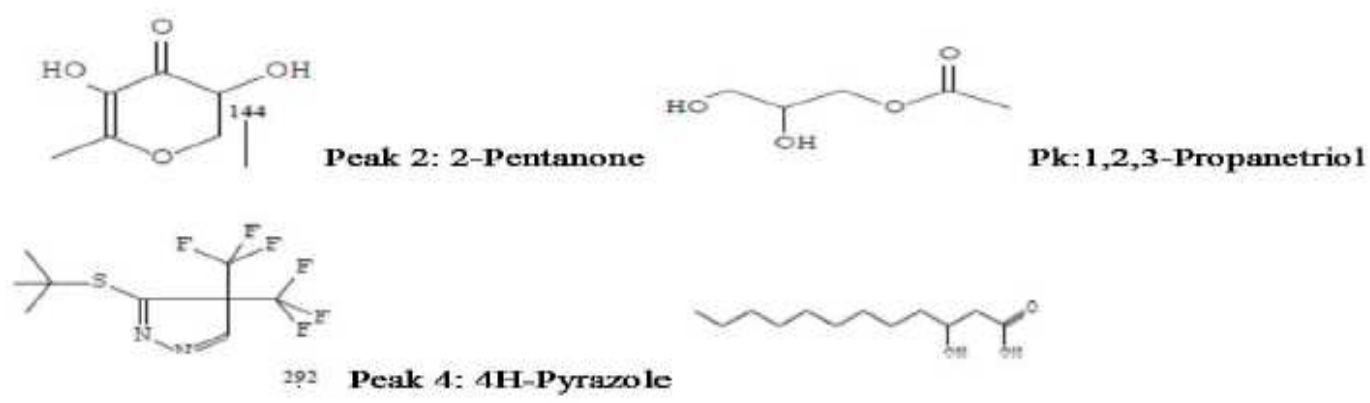

Peak 5: Dodecanoic acid

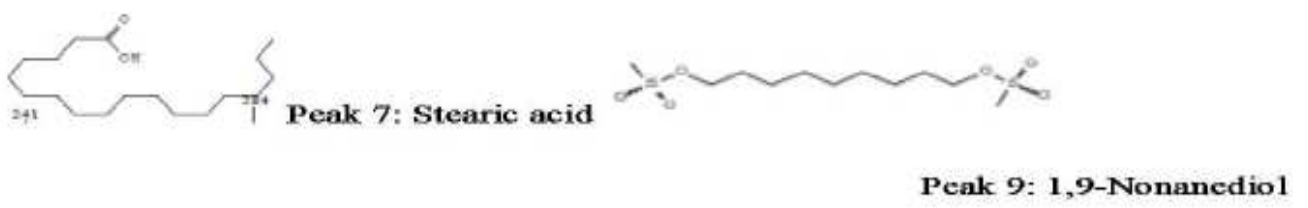

Figure 2. Structures of the compounds (peaks 2, 1, 4, 5, 7, 9) present in $G V$.

Table 6. Corrosion rate, inhibition efficiency (\% IE) and surface coverage for mild steel in a $1.0 \mathrm{M} \mathrm{HCl}$ solution, with and without a varying concentration of Grewa Venusta extract at $30^{\circ} \mathrm{C}$ for 6 days.

\begin{tabular}{cccc}
\hline Conc $(\boldsymbol{\%}$ v/v) & Corrosion rate $(\mathbf{m m p y})$ & Inhibition eff.; $\%$ IE & Surface cov. $(\boldsymbol{\theta})$ \\
\hline Blank & 51.712 & - & - \\
2 & 9.943 & 80.77 & 0.81 \\
4 & 7.751 & 85.01 & 0.85 \\
6 & 4.767 & 90.78 & 0.91 \\
8 & 1.085 & 97.9 & 0.98 \\
10 & 1.768 & 96.58 & 0.97 \\
\hline
\end{tabular}

Table 7. Effect of immersion time on inhibition efficiency of mild steel in $0.5 \mathrm{M} \mathrm{H}_{2} \mathrm{SO}_{4}$ at $30{ }^{\circ} \mathrm{C}$ in the presence of optimum concentrations of the $G V$ extract.

\begin{tabular}{|c|c|c|c|c|c|c|}
\hline \multirow{2}{*}{$\begin{array}{c}\text { Optimum } \\
\text { concentrations }\end{array}$} & \multicolumn{5}{|c|}{ Inhibition efficiency (IE \%) } \\
\cline { 2 - 7 } & $1 \mathrm{~h}$ & $2 \mathrm{~h}$ & $3 \mathrm{~h}$ & $4 \mathrm{~h}$ & $5 \mathrm{~h}$ & $6 \mathrm{~h}$ \\
\hline $\begin{array}{c}8 \% \text { v/v of Grewa } \\
\text { Venusta }\end{array}$ & 85.89 & 92.71 & $\begin{array}{c}97.9 \\
0\end{array}$ & 97.75 & 96.54 & 95.98 \\
\hline
\end{tabular}




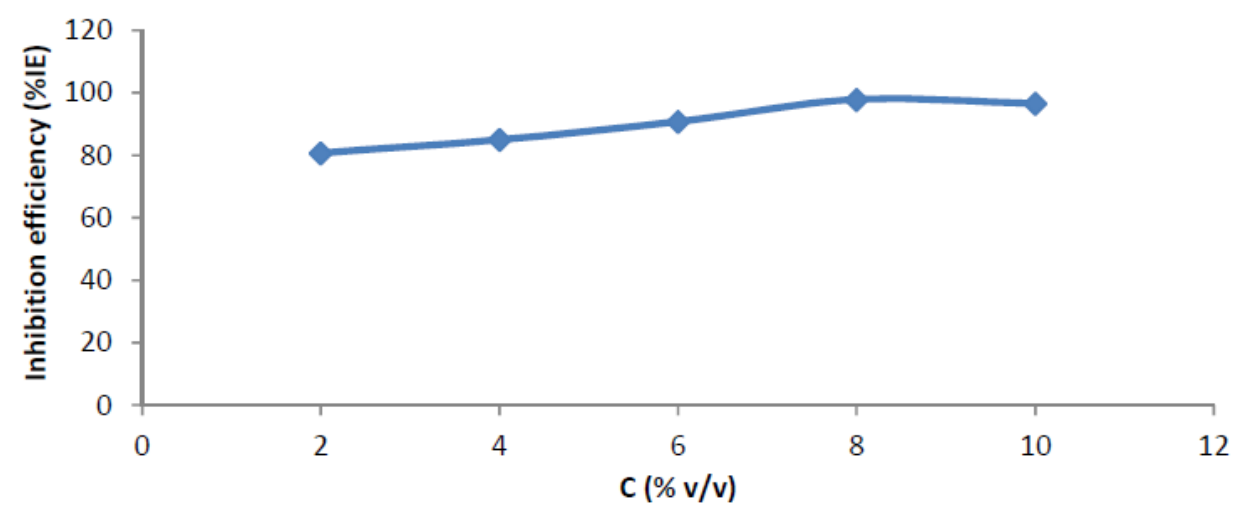

Figure 3. Variation of inhibition efficiency against concentration of extracts at $30{ }^{\circ} \mathrm{C}$.

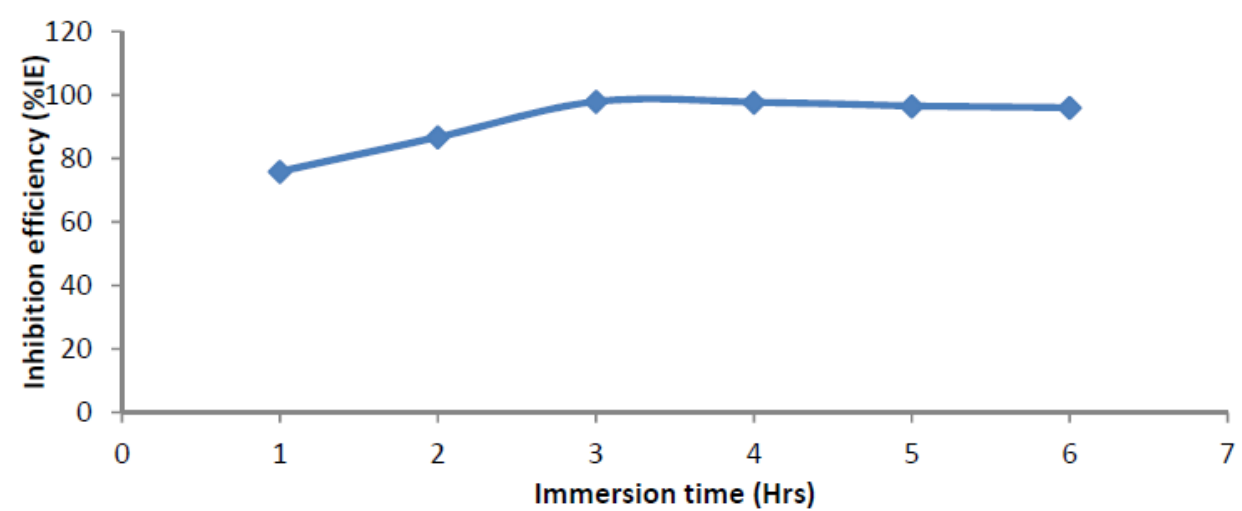

Figure 4. Variation of inhibition efficiency of $G V$ extract in $1.0 \mathrm{M} \mathrm{HCL}$ 'with immersion time.

\section{Potentiodynamic polarization measurements}

The typical Tafel polarization curves of mild steel in $1.0 \mathrm{M} \mathrm{HCl}$, in the presence and absence of Grewa venusta (wild jute tree) at different concentrations, are shown in Fig. 5.

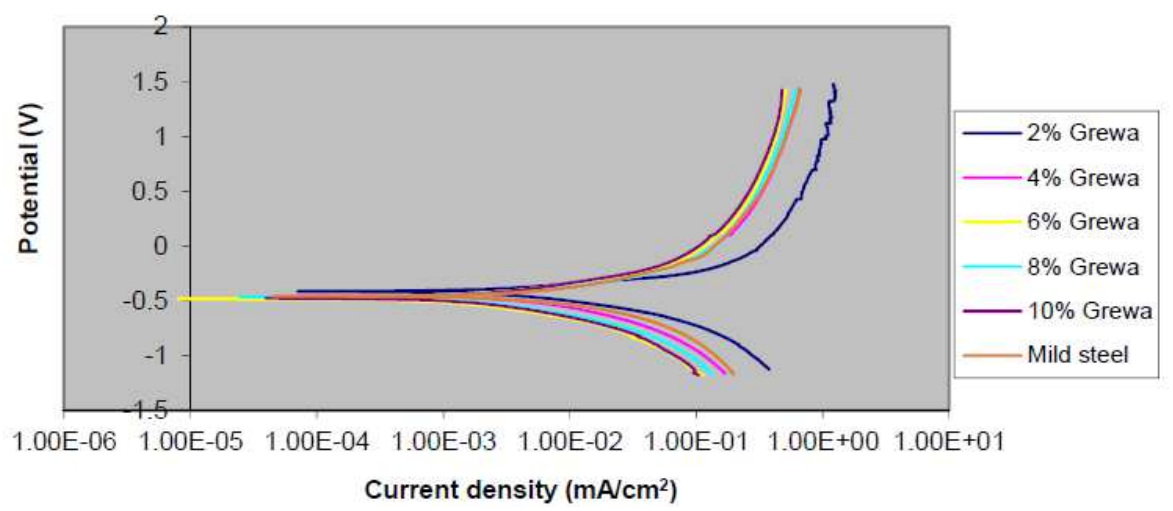

Figure 5. Potentiodynamic polarization curves for mild steel in $1.0 \mathrm{M} \mathrm{HCl}$ solution in the absence and presence of various concentrations of the $G V$ extract at $30{ }^{\circ} \mathrm{C}$.

The polarization study showed that there was the formation of a protective film formed on the metal surface during corrosion inhibition process, as observed by $[12,17]$. It could also be observed that both the cathodic and anodic reactions were suppressed with the addition of Grewa Venusta; this resulted in a protective 
film formed on the metal surface, thereby decreasing the corrosion current value (Icorr). This also suggests that Grewa Venusta reduced anodic dissolution, and also effectively retarded the hydrogen evolution reaction. The corrosion parameters, including corrosion current densities (Icorr), corrosion potential (Ecorr), cathodic Tafel slope (bc), anodic Tafel slop (ba) and inhibition efficiency (EI \%), were calculated using equation 3 [18].

Table 8. Potentiodynamic polarization parameters for mild steel in $1.0 \mathrm{M} \mathrm{HCl}$ containing different concentrations of $G V$ extract, at $30^{\circ} \mathrm{C}$.

\begin{tabular}{|c|c|c|c|c|c|}
\hline $\begin{array}{c}\text { Weight of } \\
\text { extract }\end{array}(\mathbf{g m})$ & $\begin{array}{c}\text { Ecorr } \\
/ \mathbf{~ m V}\end{array}$ & $\begin{array}{c}\text { Icorr } \\
/\left(\mathbf{m A} / \mathbf{c m}^{2}\right)\end{array}$ & $\begin{array}{c}\text { Tafel } \\
\text { slopes }\end{array}$ & $\begin{array}{c}\mathbf{m V} / \mathbf{d e c a d e} \\
\mathbf{b c}_{\mathbf{c}}\end{array}$ & $\begin{array}{c}\text { Inhibition } \\
\text { efficiency }\end{array}$ \\
\hline Blank (0) & -0.531 & 4.242 & 0.169 & 0.066 & - \\
\hline 2.00 & -0.577 & 0.9706 & 0.147 & 0.128 & 75.12 \\
\hline 4.00 & -0.565 & 0.7025 & 0.118 & 0.144 & 83.44 \\
\hline 6.00 & -0.549 & 0.4832 & 0.126 & 0.162 & 88.61 \\
\hline 8.00 & -0.552 & 0.3203 & 0.137 & 0.147 & 92.45 \\
\hline 10.00 & -0.573 & 0.2825 & 0.148 & 0.154 & 93.34 \\
\hline
\end{tabular}

The visual examination of polarization curves depicted in Fig. 5 reveals that the corrosion current density decreased as the inhibitor's concentration increased. However, the corrosion potential shifted more markedly to a negative direction. Generally, if the displacement in Ecorr is higher than $85 \mathrm{mV}$ with respect to Ecorr in an uninhibited solution, the inhibitor can be seen as of a cathodic or anodic type, as observed by $[19,20]$. From Table 8 , the maximum displacement was $46 \mathrm{mV}$, which indicates that $\mathrm{GV}$ acts as a mixed-type inhibitor at $30{ }^{\circ} \mathrm{C}$. It also shows that the effect of the inhibitor on the cathodic reaction is more observable than on the anodic reaction, and that the inhibition efficiency increased from $75.12 \%$ to $93.34 \%$ with the increment of GV concentration. Thus, this inhibitor acts as a mixed type inhibitor, and this agrees with the works of [19, 21].

\section{Adsorption isotherm}

It is evident that the corrosion inhibition process is based on the adsorption of the inhibitor molecules on the metallic surface. Generally, two modes of adsorption were always considered. Physical adsorption requires the presence of electrically charged metal surface and charged species in the bulk of the solution, while chemisorption requires charge sharing or charge transfer from the inhibitor molecule to the metal surface. In order to specify the adsorption mode of Grewa Venusta molecules on the mild steel surface in the acidic solution, the degree of surface coverage $(\theta)$, at different concentrations of the inhibitor $(\% \mathrm{v} / \mathrm{v})$ in the stagnant aerated acidic solution, was determined from the corresponding weight loss measurements, according to eq. $2[12,19]$ :

The obtained values of $\theta$ were fitted to different isotherms, including Langmuir, Frumkin, El-Awady and Temkin isotherms. The best fitting was found to obey the Langmuir adsorption isotherm in equation 4, which is based on the assumption that all adsorption sites are equivalent and that particle binding 
occurs independently from nearby sites being occupied or not, as noted by [17, 20]:

$$
\frac{\theta}{1-\theta}=K_{a d s} C
$$

where $\mathrm{C}$ is the concentration of inhibitor, $\theta$ the fractional surface coverage and $\mathrm{K}$ is the adsorption equilibrium constant related to the free energy of adsorption $\Delta \mathrm{G}_{\mathrm{ads}}$, as shown in previous work of [22]:

$$
\Delta \mathrm{G}_{\mathrm{ads}}=-2.303 \mathrm{RT} \log (55.5 \mathrm{~K})
$$

where $\mathrm{R}$ is the molar gas constant, $\mathrm{T}$ the absolute temperature, the value 55.5 is the concentration of water in a solution, expressed in mol. $\mathrm{L}^{-1}$, and $\mathrm{K}$ is the equilibrium constant. A plot of $\mathrm{C} / \theta$ as a function of $\mathrm{C}$ gives a straight line with a slope of almost unity. Such linear relationship was verified for the adsorption of Grewa Venusta on the mild steel surface, as shown in Fig. 6.

Table 9. Parameters from Langmuir isotherm for $G V$ at $30,45,60$ and $75^{\circ} \mathrm{C}$ in $1.0 \mathrm{M}$ $\mathrm{HCl}$ solution.

\begin{tabular}{|c|c|c|c|c|c|}
\hline Inhibitor & Temp. & \multicolumn{4}{|c|}{ Langmuir isotherm } \\
\hline \multirow{4}{*}{$\begin{array}{c}\text { Grewa } \\
\text { Venusta } \\
(\mathbf{G V})\end{array}$} & $\left(^{\circ} \mathbf{C}\right)$ & $\begin{array}{c}\Delta \mathbf{G} \\
\text { KJ/mol }\end{array}$ & Slope & $\mathbf{R}^{\mathbf{2}}$ & $\mathbf{K}_{\text {ads }}$ \\
\cline { 2 - 6 } & 30 & -14.558 & 0.961 & 0.996 & 5.827 \\
\cline { 2 - 6 } & 45 & -10.834 & 1.089 & 0.999 & 1.085 \\
\cline { 2 - 6 } & 60 & -10.574 & 1.115 & 0.999 & 0.821 \\
\cline { 2 - 6 } & 75 & -9.111 & 1.194 & 0.996 & 0.420 \\
\hline
\end{tabular}

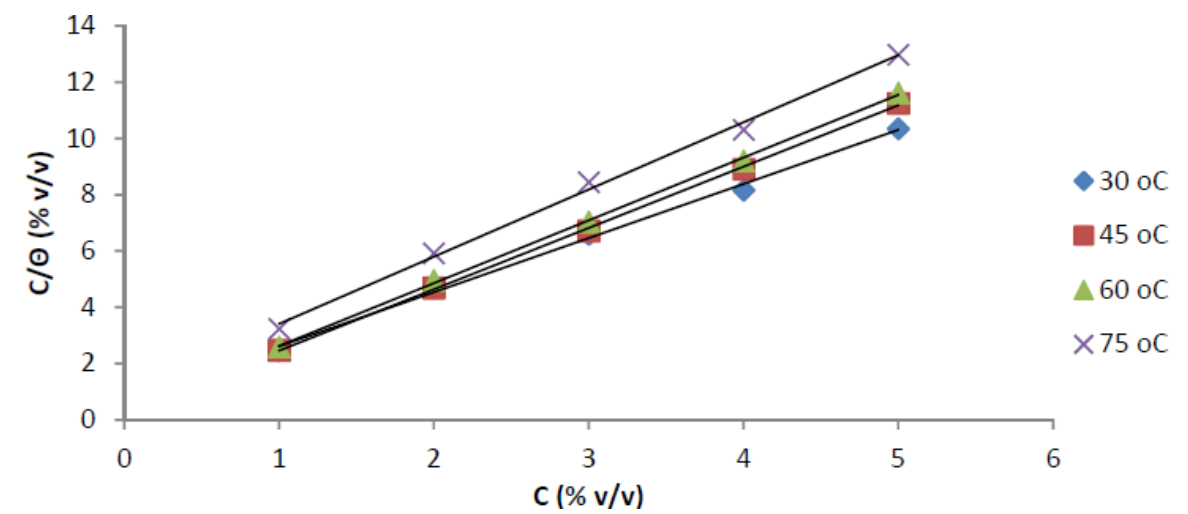

Figure 6. Langmuir adsorption isotherm for the adsorption of the $G V$ inhibitor on the mild steel surface in $1.0 \mathrm{M} \mathrm{HCl}$ solution by gravimetric method at $30,45,60$ and $75^{\circ} \mathrm{C}$.

The free energy of adsorption, $\Delta \mathrm{G}_{\mathrm{ads}}$, equilibrium constant, $\mathrm{K}_{\mathrm{ads}}$, coefficient of correlation, $\mathrm{R}^{2}$ and slopes were presented in Table 9. It is also evident that the values of equilibrium constant are relatively small and decrease with an increase in temperature, as seen from Table 8, suggesting that the interaction between the adsorbed extract molecules and mild steel surface was physisorption, which also agrees with findings of $[2,22]$. Other researchers, such as Suleiman et al. [12], claimed that any values around $-20 \mathrm{kJmol}^{-1}$ or less negative are consistent with electrostatic interaction (physisorption), while those around $-40 \mathrm{kJmol}^{-1}$ or more negative involve chemisorption, which was also supported by Khamis et al. [25]. 
Therefore, the adsorption of the investigated Grewa Venusta inhibitor molecules on mild steel is of a physical nature.

\section{Kinetics/thermodynamics consideration}

In order to study the effect of temperature on the inhibition adsorption mechanism of Grewa Venusta in an acidic solution, in absence and presence of $2-10 \% \mathrm{v} / \mathrm{v}$, studies were carried out at different temperatures (303-348 K), by weight loss measurements during 6 days of immersion time. It was noticed that the corrosion rate increases both in the uninhibited and inhibited solution, with an increase in temperature. The presence of inhibitor leads to a decrease in the corrosion rate, and inhibition efficiency also decreases with an increase in temperature, meaning that the corrosion process is temperature dependant, as observed by [24].

The results obtained are presented in Table 10 and illustrated in Fig. 7.

Table 10. Effect of temperature on mild steel corrosion in the presence and absence of $8 \%$ v/v of Grewa Venusta extract for 6 days.

\begin{tabular}{|c|c|c|c|}
\hline & $\begin{array}{c}\text { Corr. rate in the } \\
\text { absence of } \mathbf{G V}\left(\mathbf{C R}^{\mathbf{0}}\right)\end{array}$ & $\begin{array}{c}\text { Corr. rate in the } \\
\text { absence of } \mathbf{G V}(\mathbf{C R})\end{array}$ & $\begin{array}{c}\text { Inhibition } \\
\text { efficiency (\% IE) }\end{array}$ \\
\hline $\begin{array}{c}\text { Temp.( } \\
\text { K) }\end{array}$ & & & \\
\hline 303 & 51.712 & 1.085 & 97.90 \\
\hline 318 & 54.316 & 5.611 & 89.67 \\
\hline 333 & 57.319 & 7.577 & 86.78 \\
\hline 348 & 59.873 & 13.441 & 77.55 \\
\hline
\end{tabular}

It can be seen that the inhibition efficiency decreased with an increase in temperature. This might be due to the increased rate of the dissolution process of mild steel and partial desorption of the inhibitor from the metal surface with temperature. This occurrence has been reported elsewhere [18, 24].

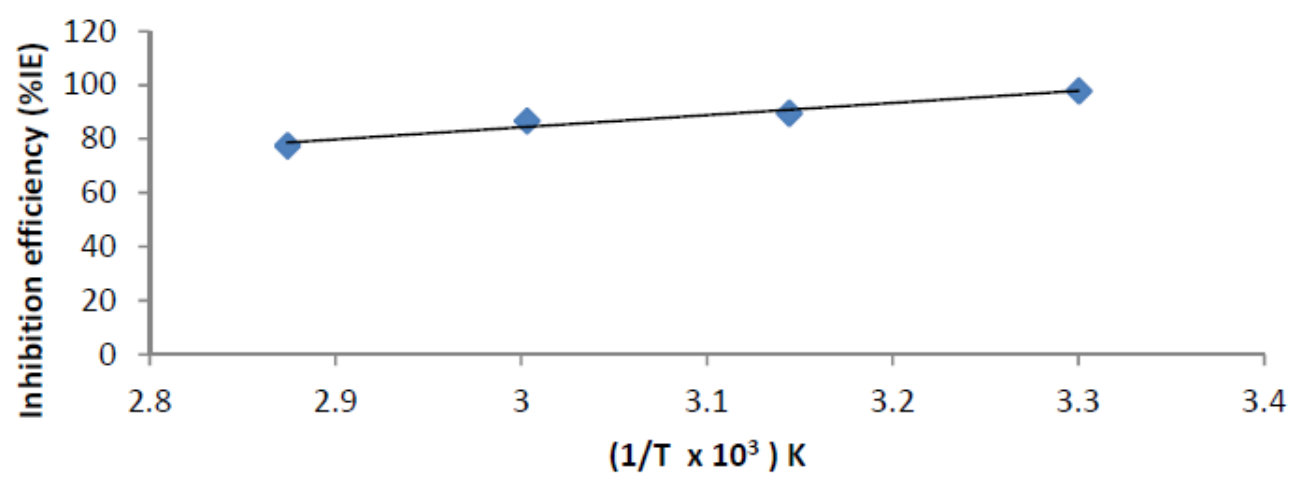

Figure 7. Variation of inhibition efficiency of extracts with temperature in a $1.0 \mathrm{M} \mathrm{HCl}$ solution.

In the presence of the extract, the inhibition efficiency increased up to a temperature of $303 \mathrm{~K}$, and after that there was a decline from $318-348 \mathrm{~K}$. Maximum inhibition efficiency was found to be $97.70 \%$ and minimum of 
$77.55 \%$, with $8 \%$ v/v concentration of Grewa Venusta extract in an acidic solution with mild steel. From previous studies [25, 26, 27], adsorption and desorption of inhibitor molecules continuously occur at the metal surface, and an equilibrium exists between these two processes at a particular temperature. This shows that there is an active-passive region in the corrosion process of mild steel in the studied environment.

It has been observed that as adsorption decreases, more desorption of the inhibitor occurs, because these two opposite processes are in equilibrium [24]. Due to a greater desorption of inhibitor molecules at higher temperatures, the bigger surface area of the mild steel in contact with aggressive environment $(\mathrm{HCl})$ results in an increase in corrosion rates, with an increase in temperature; similar works have been reported [22,28].

Accordingly, the effect of temperature change in such condition of inhibited acid-metal reaction is not uncommon. Equally, the inhibitor itself may undergo decomposition reaction. In an acidic solution, the corrosion rate is related to temperature by Arrhenius equation given in equation (6) [12]:

$$
\log (\mathrm{CR})=-\mathrm{Ea} / 2.303 \mathrm{RT}+\mathrm{A}
$$

where $\mathrm{Ea}$ is the apparent effective activation energy, $\mathrm{R}$ is the general gas constant and $\mathrm{A}$ is Arrhenius pre-exponential factor. A log plot of the corrosion rate obtained by weight loss measurement versus $1 / \mathrm{T}$ gave a straight line with a slope of $(-\mathrm{Ea} / 2.303 \mathrm{R})$ presented in Fig. 8. The values of activation energy are presented in Table 11, and the data show that the activation energy (Ea) of the corrosion rate of mild steel in $1.0 \mathrm{M} \mathrm{HCl}$ solution in the presence of the extract is higher than that in an uninhibited solution. The increase in the apparent activation energy for mild steel dissolution in an inhibited solution in this study may be interpreted as physical adsorption, which supports our earlier claim. It was also reported that an increase in the activation energy is attributed to an appreciable decrease in the adsorption of the inhibitor on the metal surface with an increase in temperature [24]. An alternative formulation of Arrhenius equation, given in equation (7) [12], was used to calculate $\Delta$ Hads and $\Delta$ Sads:

$$
C R=\frac{R T}{N h} \exp \left(\frac{\Delta S}{R}\right) \exp \left(\frac{\Delta H}{R T}\right)
$$

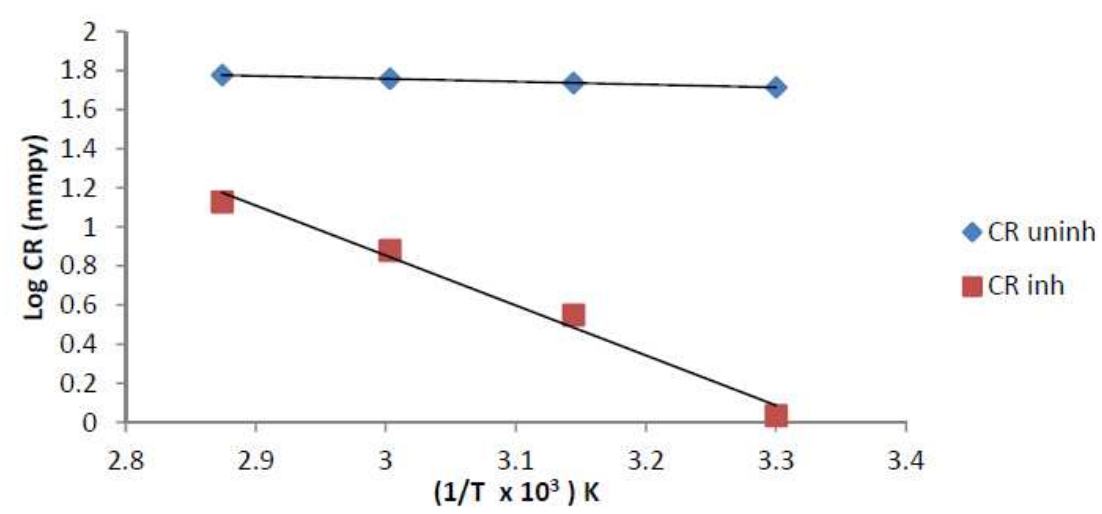

Figure 8. Variation of $\log \mathrm{CR}$ with $1 / \mathrm{T}$ for mild steel in $1.0 \mathrm{M} \mathrm{HCl}$ in the presence and absence of $G V$ concentration at $30,45,60$ and $75{ }^{\circ} \mathrm{C}$. 
Fig. 9 shows the $\log$ plots $-(\mathrm{CR} / \mathrm{T})$ versus $1 / \mathrm{T}$, which is a straight line with the slope and intercept equal to $-\Delta \mathrm{Hads} / 2.303 \mathrm{R}$ and $(\log (\mathrm{R} / \mathrm{Nh})+\Delta \mathrm{Sads} / 2.303 \mathrm{R})$, respectively.

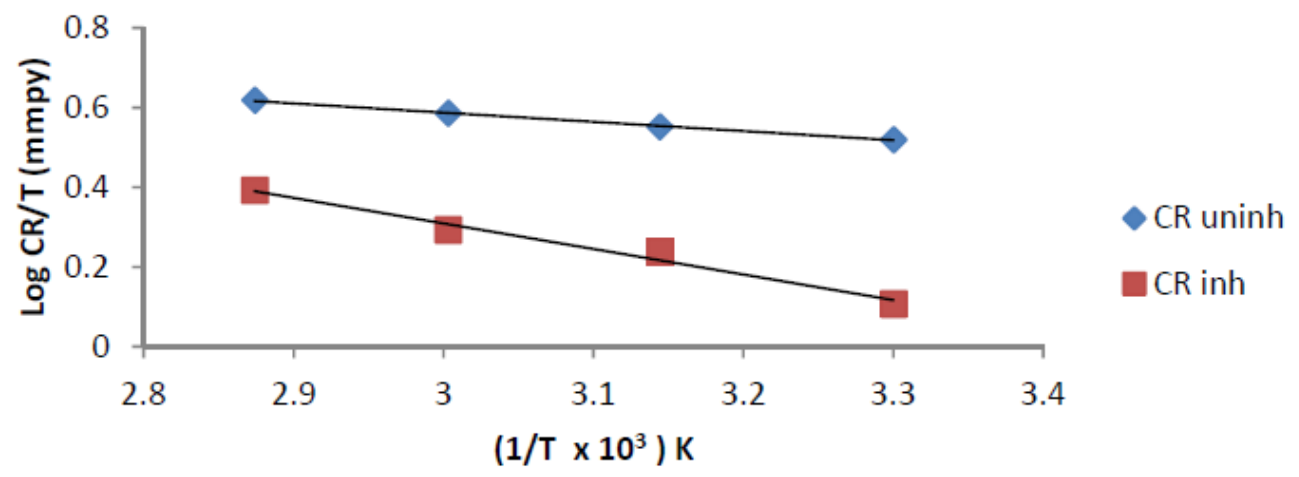

Figure 9. Variation of $\log \mathrm{CR} / \mathrm{T}$ with $1 / \mathrm{T}$ for mild steel in $1.0 \mathrm{M} \mathrm{HCl}$ in the presence and absence of $G V$ concentration at $30,45,60$ and $75{ }^{\circ} \mathrm{C}$.

Table 11. Activation parameters Ea, $\Delta H a d s$ and $\Delta S a d s$ for mild steel dissolution in 1.0 $\mathrm{M} \mathrm{HCl}$ in the absence and the presence of $\mathrm{GV}$ at $30,45,60$ and $75^{\circ} \mathrm{C}$.

\begin{tabular}{|c|c|c|c|}
\hline System/concentration & Ea $\left(\mathbf{k J m o l}^{\mathbf{1}}\right)$ & $\Delta$ Hads $\mathbf{~ K J} / \mathbf{m o l}$ & $\Delta$ Sads $(\mathbf{J} / \mathbf{m o l . K})$ \\
\hline Blank & 2.872 & 4.442 & -172.972 \\
\hline $2 \% \mathrm{v} / \mathrm{v}$ GV & 15.796 & 7.487 & -167.457 \\
\hline $4 \% \mathrm{v} / \mathrm{v} \mathrm{GV}$ & 15.781 & 7.276 & -168.893 \\
\hline $6 \% \mathrm{v} / \mathrm{v} \mathrm{GV}$ & 25.849 & 9.899 & -161.388 \\
\hline $8 \% \mathrm{v} / \mathrm{v} \mathrm{GV}$ & 38.084 & 12.292 & -154.744 \\
\hline $10 \% \mathrm{v} / \mathrm{v} \mathrm{GV}$ & 46.528 & 13.786 & -132.383 \\
\hline
\end{tabular}

From Table 11, it can be seen that values of $\Delta H a d s$ and $\Delta S a d s$ are positive and negative. The positive sign of $\Delta$ Hads indicates that the adsorption of the inhibitor molecules is an endothermic process. The values of $\Delta S a d s$ in the presence of Grewa Venusta are negative, meaning that a decrease in disordering takes place on going from reactants to the metal adsorbed species reaction complex, as observed in [11]. Still on Table 11, the values of Ea determined in the presence of Grewa Venusta are higher $\left(46.528 \mathrm{~kJ} \mathrm{~mol}^{-1}\right)$ than those of the uninhibited solution $\left(2.872 \mathrm{~kJ} \mathrm{~mol}^{-1}\right)$. The increase in the activation energy may be interpreted as physical adsorption, which satisfied our earlier claimed supported by previous works $[11,28]$.

\section{Surface morphology and adsorption isotherm}

The morphology of the samples without and with inhibitor of Grewa Venusta were examined and presented in Figs. 10a and 10b. From the surface morphology of uninhibited mild steel in $1.0 \mathrm{M} \mathrm{HCl}$ interface in Fig. 10a, severe pits, cracks and selective dissolution of intermetallic occurred, whereas there was an improvement in the surface morphology of mild steel treated with the inhibitor, in Fig. 10b. From the SEM evaluation, it is clear that some of the active constituents $\left(\mathrm{C}_{7} \mathrm{H}_{14} \mathrm{O}_{2}, \mathrm{C}_{9} \mathrm{H}_{10} \mathrm{~F}_{6} \mathrm{~N}_{2} \mathrm{~S}, \mathrm{C}_{18} \mathrm{H}_{36} \mathrm{O}_{2}, \mathrm{C}_{11} \mathrm{H}_{24} \mathrm{O}_{6} \mathrm{~S}_{2}\right.$, many O-heterocyclic rings) act as reaction centers, leading to the formation of a film on the surface of the mild steel, as proved by [25]. The inhibitor, therefore, forms protective thin layers and complexes on the mild steel surface. 


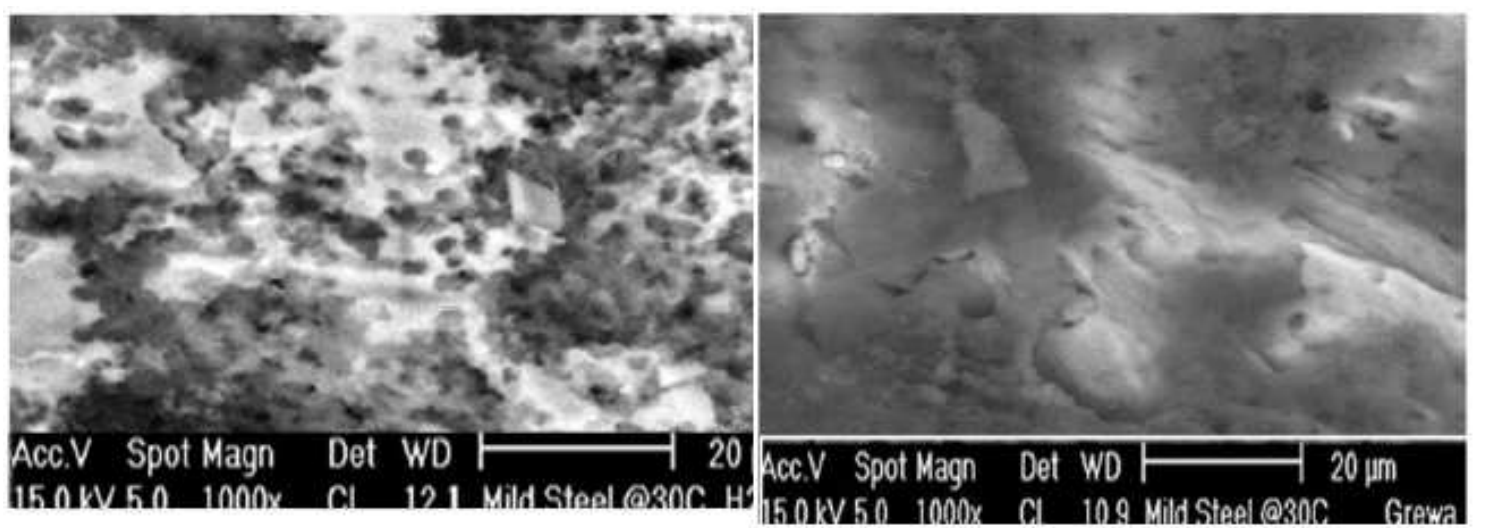

Fig.10. SEM microstructure of mild steel immersed in (a) $1.0 \mathrm{M} \mathrm{HCl}$; (b) in $1.0 \mathrm{M} \mathrm{HCl}$ with $8 \%$ v/v of Grewa Venusta.

\section{Synergism parameter}

The increase in the inhibition efficiency of organic compounds in the presence of some anions has been observed and was ascribed to synergistic effect. On that note, we considered it necessary to incorporate some halides $\left(\mathrm{KBr}^{-}, \mathrm{KCl}^{-}\right.$and $\left.\mathrm{KI}^{-}\right)$ into the environment. It was observed that $\mathrm{KI}^{-}$performed better than $\mathrm{KBr}^{-}$and $\mathrm{KCl}$, as shown in Table 12 and illustrated in Fig. 11, respectively. The inhibition efficiency of the system increased in the presence of halide ion $\left(\mathrm{KI}^{-}\right)$at the studied temperatures interval.

Table 12. Influence of halide additive $(0.5 \mathrm{M})$ on the inhibition efficiency of optimum concentration $(8 \% \mathrm{v} / \mathrm{v})$ of $G V$ at different temperatures.

\begin{tabular}{|c|c|c|}
\hline Temp $\left.{ }^{\circ} \mathbf{C}\right)$ & $\mathbf{G V}$ & $\mathbf{G V}+\mathbf{K I}$ \\
\hline 30 & 97.9 & 99.88 \\
\hline 45 & 89.67 & 95.89 \\
\hline 60 & 86.78 & 90.75 \\
\hline 75 & 77.55 & 81.97 \\
\hline
\end{tabular}

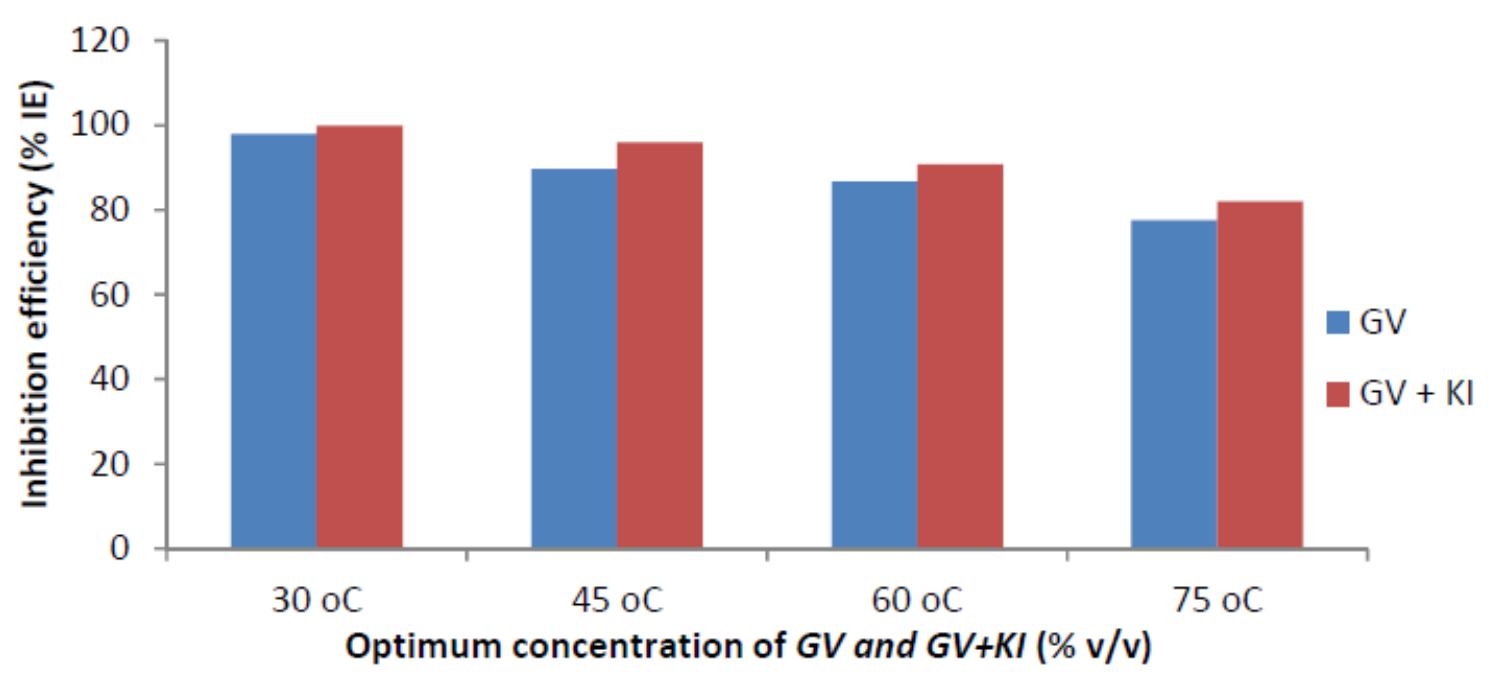

Figure 11. Influence of halide additive $(0.5 \mathrm{M})$ on the inhibition efficiency of optimum concentration $(8 \% \mathrm{v} / \mathrm{v})$ of $G V$ at different temperatures. 
It was observed that halide ions are normally adsorbed on the surface of a corroding metal, which promotes the adsorption of organic compounds by forming intermediate bridges between the positively charged metal surface and the positive end of the organic molecule. Thus, the inhibitor is adsorbed on the metal by coulombic attraction to the adsorbed halide ions on the metal surface $[12,24]$.

\section{Conclusions}

The following conclusions can be drawn from the study:

1. The characterization of the plant extract by GC-MS shows that the spectra revealed the presence of phenolic compounds like tannins, alkaloids and the aromatic compounds 2-pentanone $(22.84 \%)$, 1,2,3-propanetriol1, 4Hpyrazole, dodecanoic acid, stearic acid, and 1,9-nonanediol. The Atomic Absorption Spectroscopy (AAS) revealed the presence of calcium (greater than $77 \%$ ), followed by magnesium (16\%), manganese and chromium, while others appear to be minor.

2. Reasonable inhibition efficiencies were exhibited by the plant extract, with the corrosion rate decreasing with an increase in the concentrations of inhibitor.

3. The Langmuir adsorption isotherm fits the experimental data obtained in this study. Hence, a monolayer film was formed on the mild steel surface by the extract.

4. Based on Ea, $\Delta \mathrm{Gads}, \Delta \mathrm{Hads}$ and $\Delta \mathrm{Sads}$ values obtained in this work, physical adsorption phenomena can be proposed for the adsorption of the inhibitors.

5. Among the halides ions used, iodide has the best influence on the Grewa Venusta extract with highest inhibition efficiency of $99.88 \%$.

6. The results obtained using different corrosion analyses (gravimetric and potentiodynamic polarization) are in good agreement.

\section{Acknowledgments}

I acknowledge the efforts of Dr. Oluwagbenga Johnson, Department of Metallurgical and Materials, School of Chemical and Metallurgical Engineering, University of Witwatersrand, South Africa.

\section{References}

1. Talbot D, Talbot J. Corrosion science and technology. Florida: CRC Press LLC; 1998.

2. Badiea AM, Mohana KN. J Mater Eng Perform. 2009;18:1264-1271.

3. Singh A, Ebenso EE, Quraishi MA. Int J Corros. 2012;1-20.

4. Ahmad Z. Principles of Corrosion Engineering and Corrosion control. Elsevier: Elsevier Publishers; 2006.

5. Zamani NG, Porter JF, Mufti AA. Int J Numer Method Eng. 1986;23:12951311.

6. Ahmad Z, Patelb F. Novel Corrosion Techniques for a Green Environment. King Fahd University of Petroleum \& Minerals Dhahran, Saudi Arabia; 2011. 
7. Mayanglambam RS, Sharma V, Singh G. Port Electrochim Acta.2011;29:405-417.

8. Oguzie EE. Port Electrochim Acta. 2008;26:303-314.

9. Fontana MG. Corrosion Eng. New York: McGraw Hill; 2005.

10. Eddy N O. Port Electrochim Acta. 2009;27:579-589.

11. Lebrini M, Lecante RF, Roos A. Corrosion Science 53(2) (2011) 687-695.

12. Suleiman IY, Yaro SA, Abdulwahab M. Asian J Chem. 2016;28:242-248.

13 Doner A, Solmaz R, Ozcan M, et al. Corros Sci. 2012;53:2902-2913.

14. Anand B, Balasubramanian VA, E-J Chem. 2010;7:942-946.

15. Prakash R. Int J Electrochem Sci. 2012;7:12146-12158.

16. Al-Fakih AM, Aziz M, Sirat HM. J Mater Environ Sci. 2015;6:1480-1487.

17. Rahuma MN, Amer H, Alfergani M. Chem Science Trans. 2014;3:764-772.

18. Suleiman IY. Evaluation of Plant Extracts as Corrosion Inhibitors for Mild Steel in Acidic Environment. PhD Dissertation. Ahmadu Bello University: Zaria, Nigeria; 2013.

19. Aziate G, El Yadini A, Harhar H, et al. J Mater Environ Sci. 2015;6:18771884.

20 Ghazoui A, Zarrouk A, Bencaht N, et al. J Chem Pharm Res. 2014;6:724732.

21. Khadiri A, Ousslim A, Bekkouche K, et al. Port Electrochim Acta. 2014;32:35-50.

22. Verma1 DK, Khan F. J Adv Res. 2015;5:1-9.

23. Khamis A, Saleh MM, Awad MI, et al. J Adv Res. 2014;5:637-646.

24. Lebrini M, Lagrenee M. Corros Sci. 47(12) (2005;47:2915-2931.

25. Singh A, Ebenso EE, Quraishi M. Int J Corrosion. 2012;1-20.

26. Patel N, Rawat A, Jauharia S, et al. Eur J Chem. 2010;1:129-133.

27. Umoren SA, Ogbobe O, Igwe IO, et al. Corros Sci. 2014;85:352-359.

28. Abiola OK, Oforka NC, Ebenso EE. et al. Anti-Corrosion Method Mater. 2007;54:219-224.

29. Oguzie EE, Li Y, Wang FH. J Colloid Inter Sci. 2007;310:90-98.

30 Larabi L, Harek Y, Traisnel M, et al. J Appl Electrochem. 2004;34:833839. 